\title{
PENINGKATAN PERFORMANSI JARINGAN 4G LTE BERDASARKAN PENGECEKAN SINYAL DI KECAMATAN BUKIT SUNDI KABUPATEN SOLOK
}

\author{
Ocha Yufiansa $^{1}$, Popy Maria ${ }^{2}$, Sri Yusnita ${ }^{3}$ \\ 123 Jurusan Teknik Elektro, Politeknik Negeri Padang \\ ochayufiansa@gmail.com; popymaria@gmail.com; a3.sriyusnita@gmail.com;
}

\begin{abstract}
Abstrak - Teknologi LTE merupakan teknologi generasi keempat yang memiliki keunggulan dari teknologi sebelumnya dalam hal layanan kecepatan transfer data. Namun, kualitas layanan data akan semakin menurun seiring meningkatnya jumlah pengguna yang mengakses. Menurut APJII, pada tahun 2018 pengguna internet di Indonesia dikuasai oleh pengguna milenial. Kecamatan Bukit Sundi adalah salah satu kecamatan di Kabupaten Solok yang memiliki jumlah menara telekomunikasi paling sedikit yaitu dua menara. Namun, dibandingkan dengan kecamatan lainnya yang memiliki dua menara, Kecamatan Bukit Sundi memiliki jumlah pengguna milenial yang lebih banyak. Maka, dilakukan pengeccekan sinyal atau drive test untuk melihat bagaimana performansi jaringan 4G LTE dan bagaimana ketersediaan jaringan 4G LTE di wilayah Kecamatan Bukit Sundi. Berdasarkan hasil drive test, Kecamatan Bukit Sundi ternyata didominasi oleh RSRP (kuat sinyal) kategori lemah atau poor (RSRP -110 dBm sampai $-100 \mathrm{dBm}$ ). Untuk meningkatkan performansi jaringan 4G LTE tersebut, digunakan metode penambahan eNodeB baru (new site). Penambahan eNodeB baru dilakukan berdasarkan bad spot area. Setelah peninjauan lokasi, didapatkan titik longitude dan latitude eNodeB baru. Sedangkan untuk mendapatkan azimuth dilakukan simulasi arah sektor. Performansi jaringan kemudian diamati pada software atoll yang menunjukkan bahwa setelah penambahan eNodeB baru terjadi peningkatan RSRP bagus (-95 dBm sampai 0) dari 14,5\% menjadi $26,79 \%$.
\end{abstract}

Kata kunci: LTE, eNodeB, drive test, bad spot area.

\begin{abstract}
LTE technology is a fourth generation technology that has advantages over previous technologies in terms of data transfer speed services. However, the quality of data services will decrease with the increasing number of users accessing it. According to APJII, in 2018 internet users in Indonesia are dominated by millennial users. Bukit Sundi District is one of the districts in Solok Regency which has the least number of telecommunications towers, as much two towers. However, compared to other districts that have two towers, Bukit Sundi District has a greater number of millennial users. Then, a signal check or drive test is carried out to see how the 4G LTE network is performing and how the 4G LTE network is available in the Bukit Sundi District area. Based on the drive test results, Bukit Sundi District was in fact dominated by the weak or poor RSRP (signal strength) (RSRP -110 dBm to -100 dBm). To improve the performance of the $4 G \mathrm{LTE}$ network, a new site addition method is used. The addition of new eNodeB is based on the bad spot area. After reviewing the location, new longitude and latitude eNodeB points are obtained. Meanwhile, to get the azimuth, sector direction is simulated. Network performance was then observed in the atoll software which showed that after the addition of eNodeB there was a good increase in RSRP (-95 $\mathrm{dBm}$ to 0$)$ from $14.5 \%$ to $26.79 \%$.
\end{abstract}

Keywords: LTE, eNodeB, drive test, bad spot area.

(C) 2019 Elektron Jurnal Ilmiah

\section{PENDAHULUAN}

Teknologi LTE merupakan teknologi generasi ke empat (4G) yang diciptakan untuk memperbaiki teknologi sebelumnya. Kemampuan dari LTE terhadap teknologi sebelumnya adalah dalam hal transfer data kecepatannya hingga $100 \mathrm{Mbps}$ untuk downlink, dan 50 Mbps untuk uplink. Peningkatan jumlah layanan komunikasi internet mendasari munculnya teknologi 4G LTE, karna memberikan kemudahan bagi pengguna internet untuk mengakses data secara mobile. Peningkatan jumlah pelanggan akan memberikan pengaruh pada kualitas data yang diterima. Semakin banyak pengguna yang mengakses, maka kualitas akan semakin menurun karena prinsipnya adalah sharing bandwidth. Agar kualitas layanan yang diterima masih terjaga, operator perlu mempertimbangkan lebar bandwidth atau jumlah site. [1]

Pada tahun 2018 terdapat 171,71 juta pengguna internet di Indonesia yang apabila dilihat dari segi 
umur, maka pengguna internet tersebut dikuasai oleh milenial. Diketahui, milenial merupakan kelompok orang yang lahir pada awal tahun 1980-an hingga awal 2000-an. Data tersebut diungkap oleh Asosiasi Penyelenggara Jasa Internet Indonesia (APJII). [2]

Kabupaten Solok merupakan salah satu kabupaten di Sumatera Barat yang membutuhkan infrastruktur Telekomunikasi [3]. Kabupaten Solok memiliki 14 kecamatan dengan luas wilayah seluas $3.728 \mathrm{~km}^{2}$. Diantara 14 kecamatan tersebut, terdapat empat kecamatan yang memiliki menara telekomunikasi paling sedikit dengan jumlah dua menara telekomunikasi. [4] Jika dilihat jumlah penduduk milenial (penduduk usia 15-39 tahun) berdasarkan kecamatan tersebut, Kecamatan Bukit Sundi memiliki jumlah penduduk milenial yang lebih banyak dibandingkan tiga kecamatan lainnya, yaitu sebanyak 8431 jiwa. [5] Berdasarkan latar belakang itu dilakukan analisis untuk mengetahui performansi dari dua eNodeB yang ada di Kecamatan Bukit Sundi. Analisis performansi dilakukan berdasarkan hasil record data kualitas sinyal secara real time dari dua eNodeB dengan parameter RSRP.

Bad spot area adalah area yang memiliki parameter belum optimal. Pada penelitian [6] dilakukan analisis pada permasalahan yang meneyababkan penurunan nilai parameter di suatu area yang belum optimal dan pemecahan masalah untuk peningkatan kinerja. Kemudian pada penelitian [7] dipilih lokasi yang memiliki bad spot untuk dilakukan drive test dan optimasi di lokasi tersebut.Terdapat dua solusi untuk mengatasi masalah bad spot area yakni konfigurasi antena dan penambahan site [8]. Contoh penelitian yang menggunakan konfigurasi antena dalam mengatasi bad spot area dilakukan oleh [6] namun pada penelitian tersebut, perubahan tilting (mengatur arah sudut elevasi antena) mempengaruhi cakupan dan menyebabkan penurunan kuat sinyal pada beberapa area.

Peningkatan performansi jaringan 4G LTE dengan penambahan eNodeB baru telah dilakukan oleh [9] yang melakukan pengecekan sinyal di Kecamatan Batipuh Kabupaten Tanah Datar dengan penambahan satu eNodeB baru. Penelitian serupa juga telah dilakukan oleh [10] yang melakukan pengecekan sinyal dari daerah Kalawi Kecamatan Kuranji sampai daerah Gurun Laweh Kecamatan Nanggalo Kota Padang, dengan penambahan satu eNodeB baru. Namun, penelitian mengenai peningkatan performansi jaringan 4G LTE dengan penambahan eNodeB baru berdasarkan pengecekan sinyal, belum pernah dilakukan di daearah Kecamatan Bukit Sundi Kabupaten Solok.

Oleh sebab itu dilakukan penelitian mengenai penambahan eNodeB baru berdasarkan bad spot area dengan memperhatikan titik keramaian dan keadaan lokasi eNodeB baru, agar penambahan
eNodeB baru menjadi lebih efektif untuk ditambah di daerah yang diamati. Serta untuk memenuhi ketersediaan jaringan $4 \mathrm{G}$ bagi pengguna di Kecamatan Bukit Sundi. Penelitian ini juga dilakukan untuk mengetahui performa dua menara telekomunikasi di Kecamatan Bukit Sundi, menganalisa hasil pengecekan kualitas sinyal yang dilakukan di daerah Kecamatan Bukit Sundi, serta untuk mengetahui pengaruh penambahan eNodeB baru terhadap kualitas sinyal di Kecamatan Bukit Sundi.

\section{METODE}

A. Diagram Alir Peningkatan Performansi

Diagram alir peningkatan performansi pada penelitian ini adalah seperti pada gambar 1 .

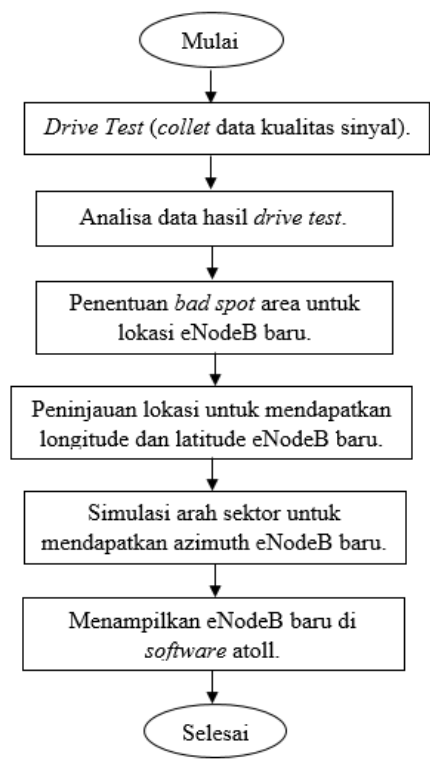

Gambar 1. Diagram Alir Peningkatan Peformansi

Tahap peningkatan performansi seperti terlihat pada gambar 1 adalah:

1. Drive Test

Kegiatan ini dilakukan selama dua hari di Kecamatan Bukit Sundi, dengan menggunakan TEMS pocket dan menghasilkan data yang disebut logfile untuk melihat kuat sinyal di Kecamatan Bukit Sundi.

2. Analisa data hasil drive test

Pengolahan logfile dilakukan dengan menggunakan software TEMS discovery. Parameter yang dilihat pada olah data ini adalah RSRP dan RSRQ, dimana nilainya dilihat berdasarkan target KPI Telkomsel.

3. Penentuan bad spot area

Tahap ini dilakukan pada software google earth yaitu dengan dilakukan pengukuran panjang bad spot area.

4. Peninjauan lokasi

Peninjauan lokasi bertujuan untuk mendapatkan posisi eNodeB baru serta 
mendapatkan koordinat longitude dan latitudenya. Kegiatan ini dilakukan dengan langsung mengamati lokasi dan menentukan beberapa titik yang dinilai cocok untuk menjadi lokasi eNodeB baru.

5. Simulasi arah sektor

Proses ini dilakukan pada software google earth yang bertujuan untuk mendapatkan arah pancaran sinyal atau azimuth eNodeB baru.

6. Menampilkan eNodeB baru pada software atoll.

Tahap ini dilakukan pada software atoll untuk menampilkan eNodeB baru beserta coveragenya. Pada tahap ini juga dapat dilihat bagaimana coverage kuat sinyal sebelum dan sesudah dirancang eNodeB baru pada daerah dirancangnya eNodeB baru.

\section{B. Referensi}

Di dalam penelitian yang dibahas oleh [8] menejelaskan bahwa terdapat dua solusi untuk mengatasi masalah bad spot area yakni konfigurasi antena dan penambahan site.

Namun di dalam penelitian yang dilakukan oleh [6] yang melakukan konfigurasi antena dalam mengatasi bad spot area, yaitu dengan melakukan perubahan tilting (mengatur arah sudut elevasi antena) mempengaruhi cakupan dan menyebabkan penurunan kuat sinyal pada beberapa area.

Penambahan site telah dibahas dalam penelitian [11] dimana eNodeB yang dibangun terdiri dari eNodeB baru dengan link fronthaul dan tanpa link fronthaul. Hasil perencanaan fronthaul microwave frekuensi $71 \mathrm{GHz}$ di tiga kecamatan Purwokerto, dilihat pada sisi radio akses, terutama dari sisi coverage, dengan rata-rata RSRP $-91,7 \mathrm{dBm}$ dan CINR sebesar 13,94 dBm, maka capacity meningkat 90,7 Mbps dengan persentase kenaikan $83 \%$.

Secara umum penelitian penambahan site yang dilakukan oleh [12] dan [13] dilakukan dengan penentuan jumlah eNodeB baru yang akan ditambah. Peneltian yang dilakukan oleh [12] menghasilkan jumlah eNodeB setiap tahun mengalami pertambahan yakni dari 10 eNodeB menjadi 12 eNodeB. Kemudian untuk penelitian yang dilakukan oleh [13] menjelaskan bahwa untuk meningkatkan parameter kualitas sinyal RSRP, SINR dan Throughput di tol Soreang Pasirkoja dibutuhkan sebanyak 10 site.

LTE merupakan pengembangan dari teknologi sebelumnya, yaitu UMTS (3G) dan HSPA (3.5G) yang mana LTE disebut sebagai generasi ke-4 (4G). Teknologi UMTS memiliki kecepatan transfer data maksimum 2 Mbps, pada HSPA kecepatan transfer data mencapai 14 Mbps pada sisi downlink dan 5,6 Mbps pada sisi uplink sedangkan pada LTE, kemampuan dalam memberikan kecepatan dalam hal transfer data dapat mencapai $100 \mathrm{Mbps}$ pada sisi downlink dan 50 Mbps pada sisi uplink dengan bandwidth channel $20 \mathrm{MHz}$.[14]

Drive test digunakan untuk outdoor (luar ruangan) karena dilakukan dengan berkendara (drive) mobil sedangkan walk test untuk indoor (dalam ruangan) karena dilakukan dengan berjalan (walk). Drive test merupakan langkah awal proses, dengan tujuan untuk mengumpulkan data pengukuran yang berkaitan dengan lokasi pengguna. Setelah data terkumpul sepanjang luas cakupan RF yang diinginkan, maka data ini akan diproses pada suatu perangkat lunak tertentu.[10] TEMS (Test Mobile System) merupakan salah satu perangkat yang dapat digunakan untuk mengamati jaringan seluler. Salah satu jenis perangkat TEMS adalah TEMS Pocket. TEMS Pocket merupakan alat diagnostik jaringan seluler yang ditanamkan kedalam telepon genggam. TEMS Pocket dapat mengukur performansi pengiriman data pada saat downlink maupun uplink. Hasil pengukuran tersebut dapat disimpan untuk dianalisis diproduk lain seperti TEMS Discovery dan TEMS Investigation.[15]

\section{HASIL DAN PEMBAHASAN}

\section{A. Analisa Hasil Drive Test}

\section{RSRP}

RSRP atau kuat sinyal adalah salah satu parameter yang digunakan dalam drive test jaringan 4G LTE. Pada penelitian ini, RSRP menjadi acuan untuk menentukan titik-titik atau area bad spot di Kecamatan Bukit Sundi, yang menjadi salah satu alasan untuk dirancang eNodeB baru pada area tersebut.

Hasil drive test yang diolah pada software TEMS discovery dengan parameter RSRP adalah seperti pada gambar 2 .

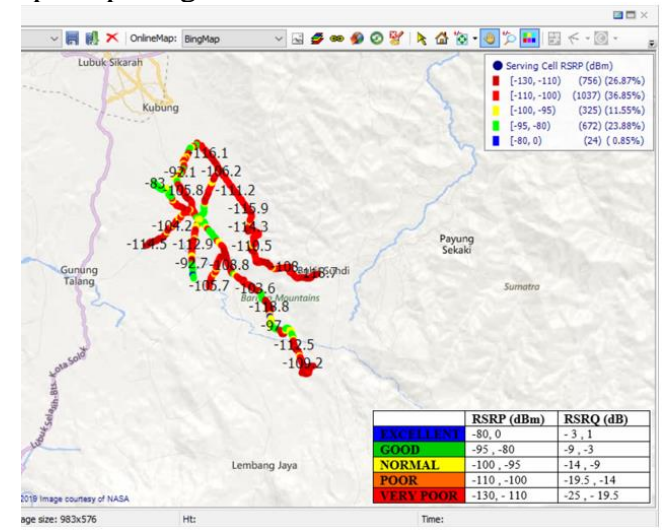

Gambar 2. RSRP di Wilayah Kecamatan Bukit Sundi

Pada gambar 2 diatas terlihat bahwa kuat sinyal di Kecamatan Bukit Sundi adalah poor karena didominasi oleh warna oranye dengan kuat sinyal dengan nilai antara -110 sampai dengan -100 dBm. RSRP yang poor tersebut terdiri dari 1037 sampel atau sebanyak 36,85\%. Sedangkan sampel RSRP yang paling sedikit 
yaitu yang berwarna biru (excellent) dengan jumlah sampel hanya 24 sampel atau sebanyak $0,85 \%$. Untuk lebih jelasnya, dapat dilihat pada diagram lingkaran pada gambar 3 .

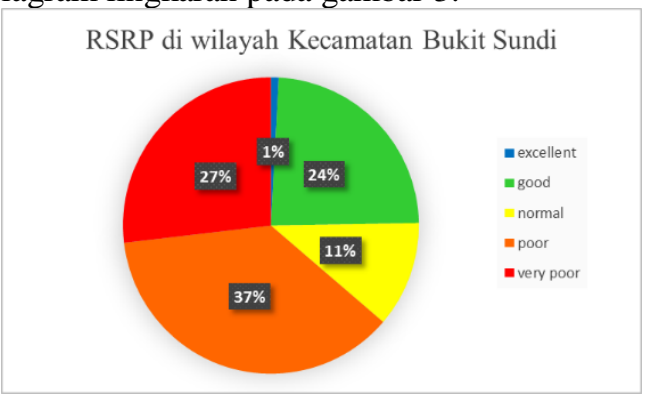

Gambar 3. Diagram Lingkaran RSRP di Kecamatan Bukit Sundi

RSRP dengan nilai poor dan very poor adalah kuat sinyal dengan kategori lemah. Berdasarkan diagram lingkaran pada gambar 3 diatas, terlihat bahwa kuat sinyal di wilayah Kecamatan Bukit Sundi, didominasi oleh nilai poor dan very poor. Artinya, RSRP jaringan 4G LTE operator telkomsel di Kecamatan Bukit Sundi, masih tergolong lemah.

\section{RSRQ}

RSRQ merupakan kualitas sinyal yang diterima oleh user equipment (UE). RSRQ merupakan parameter yang juga diamati pada penelitian ini. Tujuannya adalah untuk melihat bagaimana hubungan antara RSRQ dengan RSRP. Kemudian, berdasarkan kegiatan drive test yang telah dilakukan, didapatkan hasil pengolahan logfile pada TEMS discovery seperti pada gambar 4.

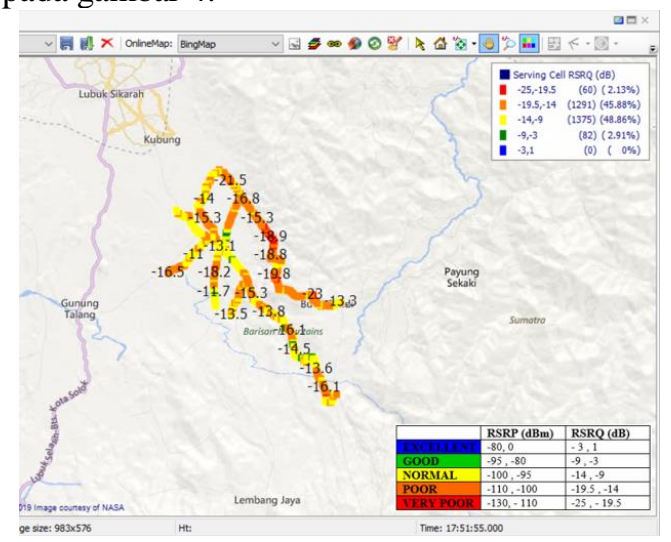

Gambar 4. RSRQ Wilayah Kecamatan Bukit Sundi

Berdasarkan gambar 4 diatas, RSRQ wilayah Kecamatan Bukit Sundi didominasi oleh nilai antara -14 sampai dengan -9 dB dengan kategori normal. RSRQ tersebut terdiri dari 1375 sampel atau sebanyak $48,86 \%$. Sedangkan RSRQ dengan jumlah sampel paling kecil adalah kategori excellent dengan jumlah sampel adalah 0 sampel yang artinya, belum ada daerah dengan jangkaun sinyalnya yang excellent. Untuk lebih jelasnya RSRQ wilayah Kecamatan Bukit Sundi dapat dilihat pada diagram lingkaran pada gambar 5 .

RSRQ di wilayah Kecamatan Bukit Sundi

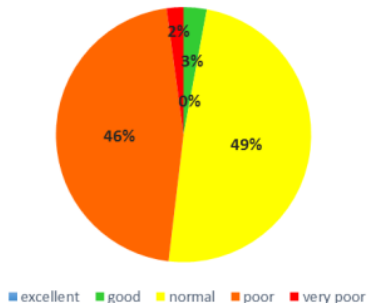

Gambar 5. Diagram Lingkaran RSRQ di Kecamatan Bukit Sundi

Berdasarkan gambar 5 diatas, terlihat bahwa kualitas sinyal di Kecamatan Bukit Sundi didominasi oleh warna kuning dan oranye atau didominasi oleh kategori normal dan lemah. Untuk kategori excellent tidak terlihat pada diagram karena jumlah sampelnya yang 0 atau tidak ada. Walaupun kuat sinyal di Kecamatan Bukit Sundi tidak mencapai kategori paling bagus atau excellent, namun kualitas sinyal jaringan 4G operator telkomsel di Kecamatan Bukit Sundi sudah cukup baik karena hampir setengah sampel kualitas sinyal di Kecamatan Bukit Sundi berkategori normal.

3. Letak eNodeB Existing Pada Google Earth

Hasil pengolahan data drive test dilakukan pada software TEMS discovery. Kemudian hasil dari software tersebut dapa diexport ke format KML/KMZ, yaitu format file untuk dapat diopen pada software google earth. Berikut adalah posisi eNodeB existing terlihat seperti pada gambar 6 .
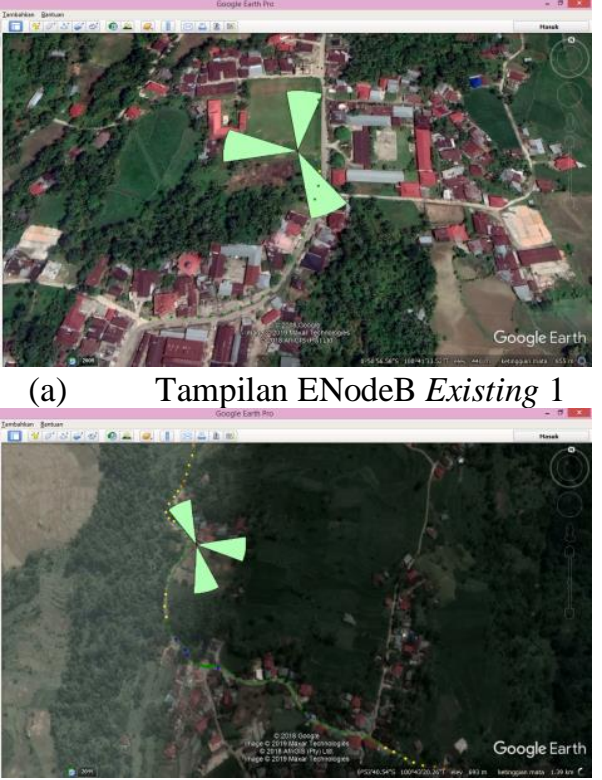

(b) Tampilan ENodeB Existing 2

Gambar 6. Tampilan EnodeB Existing 
Gambar 6 merupakan tampilan eNodeB Existing di Kecamatan Bukit Sundi. eNodeB existing 1 terletak di Nagari Muara Panas Kecamatan Bukit Sundi dengan site ID yaitu SLK506ML_Muara Panas. Kemudian, eNodeB existing 2 adalah eNodeB yang terletak di Nagari Dilam dengan site ID yaitu SLK604ML_Dilam.

\section{B. Hasil Pengukuran Titik-Titik Bad Spot Area}

Pengukuran panjang bad spot area telah dilakukan pada software google earth, dimana bad spot area tersebut dilihat berdasarkan RSRP dengan kategori very poor $(-130 \mathrm{dBm}$ sampai dengan -110 $\mathrm{dBm})$. Daerah yang diukur tersebut adalah seperti pada gambar 7 .

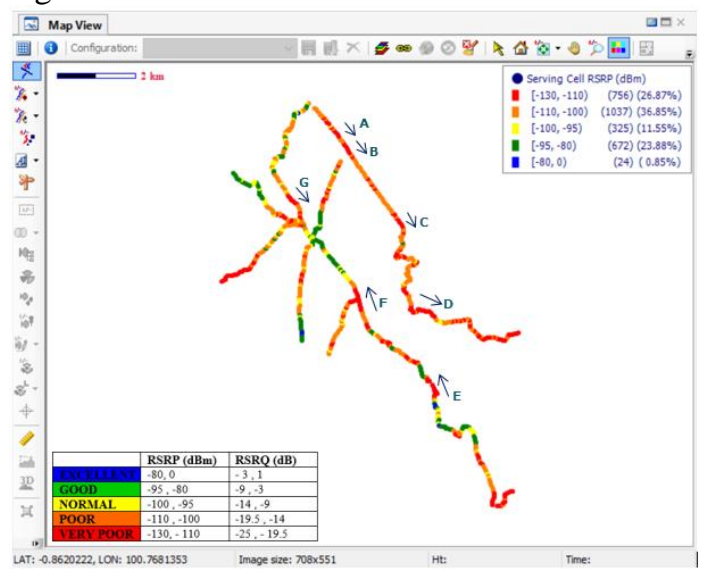

Gambar 7. Daerah-daerah yang Diukur Panjangnya adalah:

Hasil pengukuran daerah-daerah pada gambar 7

Tabel 2. Hasil Pengukuran Titk-titik Bad Spot

\begin{tabular}{|l|l|}
\hline & Panjang \\
\hline A & $221,70 \mathrm{~m}$. \\
\hline B & $333,93 \mathrm{~m}$. \\
\hline C & $263,22 \mathrm{~m}$. \\
\hline D & $482,95 \mathrm{~m}$. \\
\hline E & $533,68 \mathrm{~m}$. \\
\hline F & $604,60 \mathrm{~m}$. \\
\hline $\mathrm{G}$ & $331,46 \mathrm{~m}$. \\
\hline
\end{tabular}

Berdasarkan pengukuran pada hasil collect data kuat sinyal pada tabel 2, terlihat bahwa daerah dengan bad spot area terpanjang adalah daerah $\mathrm{F}$. Daerah F adalah salah satu wilayah di Nagari Kinari, Kecamatan Bukit Sundi. Kemudian, karena daerah F adalah daerah dengan bad spot area yang paling panjang dibandingkan dengan daerah lain yang telah diukur dan daerah $F$ juga terletak pada titik keramaian, maka daerah $\mathrm{F}$ dipilih sebagai lokasi untuk perancangan eNodeB baru.

\section{Hasil Peninjauan Lokasi}

Peninjauan lokasi dilakukan bertujuan untuk mendapatkan titik koordinat eNodeB baru.
Peninjauan lokasi dilakukan dengan mendatangi daerah $\mathrm{F}$ dan melihat beberapa tempat yang dianggap cocok untuk eNodeB baru. Dari hasil peninjauan lokasi, didapatkan tiga lokasi yang akan dipilih satu lokasi dengan beberapa pertimbangan diantaranya, lokasi yang mudah diakses selama pembangunan berlangsung, lokasi yang strategis, dan kondisi lokasi yang memungkinkan untuk dilakukan pembangunan tower.

Lokasi A, B dan C adalah lokasi yang mudah diakses karena terletak tidak jauh dari jalan utama. Kemudian dengan penentuan arah sektor yang baik, lokasi A, B, dan C juga merupakan lokasi yang strategis agar daerah pertigaan dengan bad spot ini bisa mendapatkan kuat sinyal yang lebih bagus. Namun secara keadaan kondisi tanah pada ketiga lokasi ini, lokasi C lebih bagus daripada lokasi A dan B karena lokasi A dan B tersebut merupakan daerah persawahan. Lokasi C lebih memungkinkan untuk dibangun menara telekomunikasi daripada lokasi A dan B. Selain itu, lokasi C juga terletak di tengahtengah pertigaan sehingga penyebaran kuat sinyal yang diharapkan bisa lebih merata.

Dengan menggunakan aplikasi UTM Geo Map pada smartphone, maka didapatkan titik koordinat untuk lokasi eNodeB baru yaitu untuk longitude adalah $100^{\circ} 42^{\prime} 1.79$ " dan untuk latitude adalah 0 51'59.76'. Posisi eNodeB baru jika dilihat pada software google earth adalah seperti pada gambar 8 .

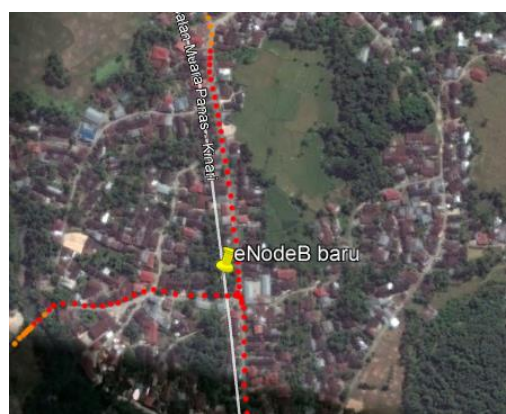

Gambar 8. Lokasi ENodeB Baru

\section{Hasil Simulasi Sektor}

Simulasi sektor dilakukan pada software google earth dengan menginputkan titik koordinate eNodeB baru terlebih dahulu. Kemudian, didapatkan arah ketiga sektor eNodeB baru tersebut seperti pada gambar 9.

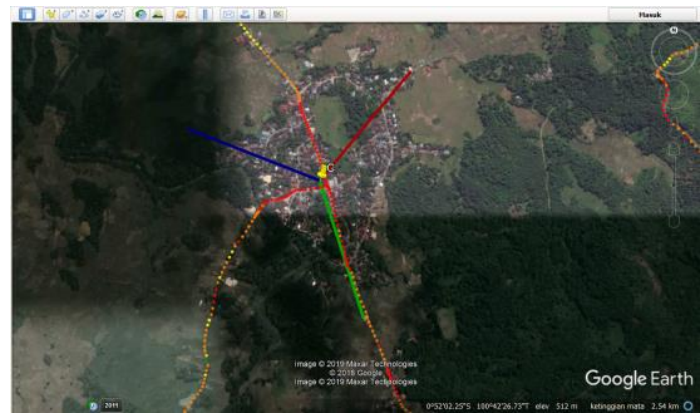

Gambar 9. Arah Sektor ENodeB Baru 
Gambar 9 diatas menunjukkan arah sektor eNodeB baru. Dimana, garis yang berwarna merah merupakan sektor 1 , kemudian garis yang berwarna hijau merupakan sektor 2 dan garis yang berwarna biru merupakan sektor 3. Azimuth eNodeB baru berdasarkan arah sektor tersebut adalah seperti pada tabel 3.

Tabel 3. Azimuth ENodeB Baru

\begin{tabular}{|l|l|}
\hline Nama & \multicolumn{1}{|c|}{ Azimuth } \\
\hline Sektor 1 & $39^{\circ}$ \\
\hline Sektor 2 & $162^{\circ}$ \\
\hline Sektor 3 & $291^{\circ}$ \\
\hline
\end{tabular}

E. Hasil Tampilan eNodeB Baru Pada Google Earth Setelah mendapatkan informasi atau data eNodeB baru yaitu longitude, latitude serta azimuthnya, maka eNodeB baru sudah bisa ditampilkan pada software atoll serta dilihat coverage areanya. Setelah diinputkan titik eNodeB baru, maka tampilannya pada software atoll adalah seperti pada gambar 10 .

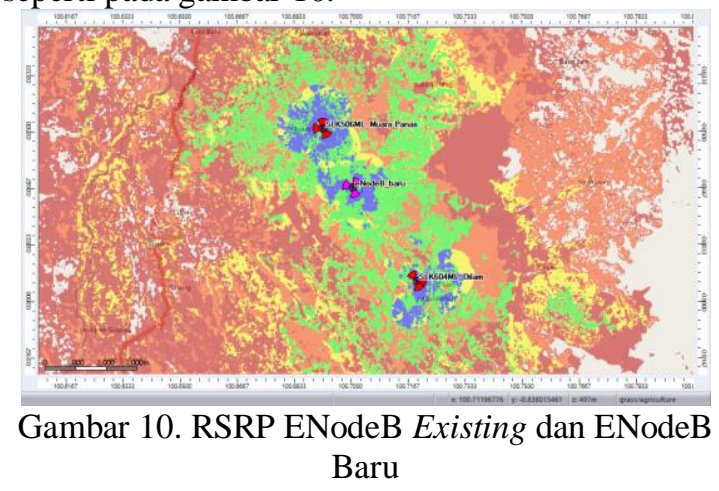

Gambar 10 adalah tampilan eNodeB baru beserta coverage sinyalnya yang telah dicalculate pada software atoll.

F. Analisa Penambahan eNodeB Baru Untuk Peningkatan Performanasi

Setelah dilakukan proses pengecekan sinyal di Kecamatan Bukit Sundi, maka dilakukan pengolahan data hasil pengecekan sinyal. Berdasarkan hasil pengolahan data tersebut, didapatkan analisis bahwa RSRP atau kuat sinyal di Kecamatan Bukit Sundi didominasi oleh RSRP dengan kategori poor dan very poor. Artinya, jaringan 4G LTE di Kecamatan Bukit Sundi masih lemah dan membutuhkan peningkatan performansi jaringan 4G LTEnya.

Solusi yang dilakukan untuk peningkatan performansi tersebut adalah penambahan eNodeB baru. Maka dilakukan perancangan eNodeB baru dengan tahapan menentukan lokasi eNodeB baru berdasarkan bad spot area, hingga didapatkan longitude dan latitude eNodeB baru. Selanjutnya dilakukan simulasi sektor untuk mendapatkan azimuth atau arah pancaran sinyal eNodeB baru.
Setelah data informasi eNodeB baru didapatkan, maka dilihat bagaimana histogram covergae kuat sinyal di Kecamatan Bukit Sundi sebelum dan setelah penambahan eNodeB baru. Proses ini dilakukan pada software Atoll. Histogram coverage kuat sinyal sebelum dan setelah penambahan eNodeB baru adalah seperti pada gambar 11 dan gambar 12.

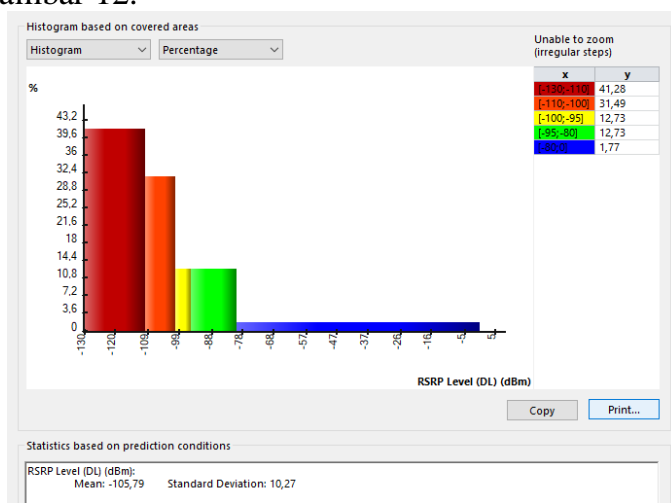

Gambar 11. Histogram Coverage Kuat Sinyal Before

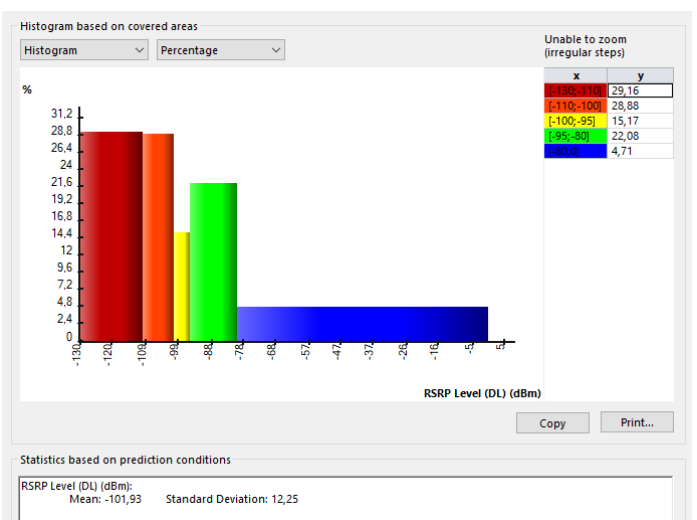

Gambar 12. Histogram Coverage Kuat Sinyal After

Gambar 11 adalah histogram coverage kuat sinyal di Kecamatan Bukit Sundi sebelum penambahan eNodeB baru dan gambar 12 adalah histogram setelah penambahan eNodeB baru. Kemudian berdasarkan histogram tersebut dilihat persentase RSRP yang bagus yaitu dengan kategori good dan excellent atau yang berwarna biru dan hijau. Persentasi RSRP tersebut adalah:

a. Coverage kuat sinyal RSRP bagus sebelum penambahan eNodeB baru.

Total $=\%$ RSRP kategori good $+\%$ RSRP kategori excellent

$=12,73 \%+1,77 \%$

$=14,5 \%$

b. Coverage kuat sinyal RSRP bagus setelah penambahan eNodeB baru.

Total $=\%$ RSRP kategori good $+\%$ RSRP kategori excellent

$=22,08 \%+4,71 \%$

$=\mathbf{2 6 , 7 9 \%}$ 
Berdasarkan perhitungan tersebut, didapatkan total coverage kuat sinyal sebelum penambahan eNodeB baru adalah $14,5 \%$ sedangkan total coverage kuat sinyal setelah penambahan eNodeB baru adalah 26,79\%. Dari hasil perhitungan tersebut terlihat bahwa terjadi kenaikan persantase RSRP setelah penambahan eNodeB baru. Artinya, dengan penambahan eNodeB baru, telah meningkatan performansi kualitas sinyal jaringan 4G LTE di Kecamatan Bukit Sundi.

\section{KESIMPULAN}

Kuat sinyal jaringan 4G LTE operator telkomsel di Kecamatan Bukit Sundi, didominasi oleh sampel dengan kategori poor (-110 dBm sampai dengan $100 \mathrm{dBm})$ dan very poor $(-130 \mathrm{dBm}$ sampai dengan $-110 \mathrm{dBm}$ ) yang berarti kuat sinyalnya masih lemah. Titik-titik bad spot area pada daerah Kecamatan Bukit Sundi, ditentukan dengan pengukuran beberapa wilayah dengan bad spot yang panjang pada software google earth. Sehingga didapatkan daerah F yang terletak di Nagari Kinari sebagai lokasi perancangan eNodeB baru. Plan titik eNodeB baru dibuat dengan melakukan survey lokasi dan simulasi sektor, sehingga didapatkan titik koordinat eNodeB baru dengan longitude $100^{\circ} 42^{\prime} 1.79$ ' dan latitude 0 51'59.76". Kemudian azimuth untuk eNodeB baru adalah $39^{\circ}$ untuk sektor $1,162^{\circ}$ untuk sektor 2 dan $291^{\circ}$ untuk sektor 3. Pengaruh penambahan eNodeB baru terhadap kualitas sinyal pada bad spot area lokasi eNodeB baru adalah terjadi kenaikan persantase RSRP bagus setelah penambahan eNodeB baru, dengan persentase awal $14,5 \%$ menjadi 26,79\%. Artinya, dengan penambahan eNodeB baru, telah meningkatan performansi kualitas sinyal jaringan 4G LTE di Kecamatan Bukit Sundi.

\section{REFERENSI}

[1] A. S. Tanjung and Febrizal, "Perencanaan Jaringan Long Term Evolution (LTE) Menggunakan Parameter Existing di Universitas Riau," Jom FTEKNIK, vol. 4, no. 1, p. 1, 2017.

[2] A. T. Haryanto, "Pengguna Internet Indonesia Didominasi Milenial," Inet.Detik.Com, 2019. [Online]. Available: https://inet.detik.com/telecommunication/d4551389/pengguna-internet-indonesiadidominasi-milenial.

[3] A. Sikumbang, "Sejumlah Kabupaten di Sumbar Butuh Infrastruktur Telekomunikasi," padangkita.com, 2017. .

[4] BPSKabupatenSolok, Kabupaten Solok Dalam Angka 2019. 2019.
[5] BPSKabupatenSolok, Kecamatan Bukit Sundi Dalam Angka 2018. 2018.

[6] D. L. Tamtama and E. Y. D. Utami, "Analisis Kinerja Coverage \& Kualitas Sinyal 4G Lte Pada Operator Seluler Di Kota," Media Elektr., vol. 10, no. 2, p. 8, 2017.

[7] N. Wahyu, A. Setiawan, H. Vidyaningtyas, F. T. Elektro, and U. Telkom, "Optimasi Layanan Data Pada Jaringan Lte Dengan Genex Assistant Di Delanggu Klaten Optimization of Data Service Lte Network With Genex Assistant in Delanggu Klaten," e-Proceeding Eng., vol. 4, no. 3, p. 3532, 2017.

[8] P. T. Lelepadang, E. Y. D. Utami, and A. A. Febrianto, "Analisis Coverage Planning dan Coverage Prediction di Existing Network eNodeB Jaringan 4G di Daerah Operasional Yogyakarta dan Magelang," Techné J. Ilm. Elektrotek., vol. 17, no. 02, pp. 69-80, 2018.

[9] S. P. Lidya, "Perancangan eNodeB (evolved node b) Jaringan 4G Berdasarkan Pengecekan Sinyal di Kecamatan Batipuh Kabupaten Tanah Datar,” 2017.

[10] L. Amriva, "Perancangan evolved node b baru pada jaringan $4 \mathrm{~g}$ lte (long term evolution ) dengan metode drive test," 2017.

[11] F. P. Wibawa, M. A. Amanaf, and A. Wahyudin, "Perencanaan dan Analisis Fronthaul Microwave Menggunakan Spektrum Frekuensi $71 \mathrm{Ghz}$ untuk Radio Access Network dengan Metode Drive Test 4G LTE," Bul. Pos dan Telekomun., vol. 17, no. 1, pp. 47-60, 2019.

[12] M. Ulfah and F. F. Kurnia, "Penentuan Jumlah eNodeB Jaringan 4G/LTE di Kecamatan Penajam Kabupaten Penajam Paser Utara," J. Surya Energy, vol. 2, no. 2, pp. 179-183, 2018.

[13] Y. S. Rohmah and D. A. Nurmantris, "Perancangan Jaringan Lte Fdd Di Tol Soreang-Pasir Koja Menggunakan Software Planning," J. Elektro Telekomun. Terap. Juli 2018, pp. 623-633, 2018.

[14] I. Haromain, "Atoll - Radio planning software," 2018.

[15] N. P. Yuliani, "Pengenalan TEMS Pocket 4G," Unit Laboratorium Fakultas Ilmu Terapan, 2017. [Online]. Available: https://fit.labs.telkomuniversity.ac.id/penge nalan-tems-pocket-4g/. 